\title{
Increasing Engagement of English Learners Through Universal Design for Learning
}

\author{
Melinda S. Eichhorn \\ Gordon College \\ Amanda E. Lowry \\ Rutgers University \\ Kristen Burke \\ Gordon College
}

English learners (ELs) are the fastest growing segment of K-12 students. When ELs do not respond to instruction as quickly as their English-speaking peers, teachers may focus on their deficits and wrongly label them as having a learning disability. In this article on the universal design for learning engagement guidelines, we summarize how we have anticipated learning barriers and increased engagement with academic content for ELs in our practice. By teaching strategies for self-regulation and individual coping skills, providing guided practice and support to sustain effort, and giving students various ways to achieve the same goal in a safe learning environment, teachers of ELs and collaborative staff can engage students in their classrooms and schools. We explore universal design for learning for ELs through an assets-based approach and suggest strategies for elementary and secondary teachers to modify for ELs through illustrative case vignettes based on our classroom practice.

Keywords: engagement, English learners, learning difficulties, universal design for learning

\section{Introduction}

Cho (pseudonym) grew up in a refugee camp in Southeast Asia and had no prior school experience when he entered second grade in an urban elementary school in the Northeast United States. He spent his first month of school sleeping at his desk, adjusting to the sights and sounds of a school, and working through the trauma of his early childhood.

Hector (pseudonym) grew up with his grandparents in Central America. He arrived in the United States as an unaccompanied minor with no schooling. His first experience with schooling was in a suburban high school in the MidAtlantic. He was considered preliterate, as he could not even hold a pencil, much less write his name. He was struggling with the hardships faced during his youth and journey to the United States. Hector spent his first month at school learning how to socialize with his peers and adjusting to life in a school. 
Cho and Hector represent various students in our classrooms; however, they do not represent the background of all newcomers. Cho and Hector are English learners (ELs), the fastest growing segment of the student population in the United States (Klingner \& Eppolito, 2014). Yet, when they did not respond to classroom instruction as expected and their learning needs differed from their English-speaking peers, their general education teachers were tempted to focus on their learning deficits. Because of the linguistic differences of ELs, it can be very challenging for teachers to determine if students have learning difficulties or if they are showing typical characteristics of language acquisition, such as the silent period or slower development of academic versus conversational language. Teachers may wonder if the student has a learning disability or should qualify for special education services.

In school districts with a small number of ELs, these students are typically overrepresented in special education, while in districts with larger EL populations, students may be underrepresented in special education (Maxwell \& Shah, 2012). According to Clarke, Huang, Milczarski, \& Raby (2011), ELs are overrepresented in some special education programs because they are referred for services before the curriculum is modified for their language needs. ELs lose academic ground when classified as learning disabled and receive incorrect instruction for their actual learning needs (Clarke et al., 2011). ELs are in need of academic programs that focus on oral language proficiency to improve literacy acquisition, while generic literacy programs teach only reading and writing skills (Klingner \& Eppolito, 2014). Educators must be aware of the behaviors and characteristics of students with learning disabilities and ELs that overlap and mirror each other, such as difficulty following directions, slower processing speed, trouble identifying and manipulating sounds, and frustration with academic work. The difference between the two groups is the antecedent of the behavior. For students with a learning disability, the possible cause of their difficulty is a difference in working memory, phonological awareness, and executive functions. For ELs acquiring a new language, they may not yet have full understanding of all of the academic vocabulary in English, struggle with isolating unfamiliar phonemes that do not exist in their first language, and be mentally exhausted from code switching (Klingner \& Eppolito, 2014).

For some students, special education identification and placement is appropriate and necessary; however, for others, it may be the result of factors outside the student and unrelated to the presence of disability (Sullivan, 2011). Instead of focusing on deficits, or what they lack compared to their peers, teachers and administrators can focus on the abilities that ELs do have, what they already know, and how to incorporate these abilities in their instruction as they support them in learning new content (Molle, 2015). In other words, we can take an assets-based approach to learners rather than a deficits-based approach (Civil, 2007; Koestler, 2012).

This article focuses on increasing engagement of ELs in all school settings. While we acknowledge that some ELs may eventually need special education services, the purpose of this article is to share tools that we have used in our practice to build upon ELs' strengths and inform the special education prereferral process. In this article, we-a special education professor, an elementary English-as-asecond-language (ESL) specialist/special educator, and a high school ESL math teacher-summarize the universal design for learning (UDL) framework and principle of engagement and apply the guidelines for engagement to the case vignettes of Cho and Hector as they assimilate and learn in American schools. We recognize the importance of collaboration among professionals and gathering information from families within the UDL framework as well. Our goal is that teachers use multiple means of engagement to see the variability of ELs' profiles as an opportunity, rather than a problem, in their classroom (Center for Applied Special Technology [CAST], 2015). 


\section{Meeting the Unique Needs of All: Universal Design for Learning}

UDL was originally developed by CAST, a nonprofit organization dedicated to the improvement of teaching and learning for all types of students. Based on neuroscience research, UDL is a pedagogical framework that requires teachers to shift their thinking about students' learning differences. As teachers plan, they consider ways the curriculum can adapt to student needs, rather than require learners to adapt to an inflexible curriculum (Meo, 2008). Teachers may already be familiar with differentiated instruction as a way to develop multileveled options to challenge students within the curriculum. However, UDL extends the special purpose of learning environments by eliminating barriers through initial designs that consider the needs of diverse students rather than overcoming barriers later through individual adaptation. Using the UDL guidelines, teachers proactively create learning environments and pedagogy accessible to all students and encourage them to become more autonomous learners by embedding choices and removing learning barriers in their instruction (Novak, 2016; Rose, Harbour, Johnston, Daley, \& Abarbanell, 2006). Using the UDL framework as they plan, teachers offer their students multiple means of engagement (motivating students to learn) and representation (helping students perceive and comprehend information), as well as action and expression (allowing learners to express what they know and understand; CAST, 2018; National Center on Universal Design for Learning, 2014; Novak, 2016).

In this article, we take a closer look at the positive effects of engaging and motivating ELs to learn. We solely focus on the principle of engagement, although we acknowledge that the other two principles, multiple means of representation and action and expression, are equally important. We focus on the engagement principle because students must be interested, sustain their effort, and develop coping skill and strategies-all before they can take in knowledge, comprehend it, and express what they know.

\section{Multiple Means of Engagement}

Engagement is a crucial factor for culturally and linguistically diverse students. For learning to happen, students have to be motivated (CAST, 2015). To engage students' interest, teachers can provide activities and information that is culturally relevant and minimize threats and distractions by creating a safe space for students to learn. By offering students choices to practice and assess skills, as well as varying the options for tools and supports, teachers can increase students' engagement with academic content (CAST, 2018). CAST has organized the principle of engagement into three guidelines: provide options for self-regulation, provide options for sustaining effort and persistence, and provide options for recruiting interest within a safe learning environment.

\section{Provide Options for Self-Regulation}

Teachers can promote expectations and beliefs that optimize engagement, including facilitating individual goal setting and dealing with frustration and anxiety (CAST, 2018). Because some newcomers make social, emotional, and learning adjustments in their new environment, they may need suggestions for alternative strategies to manage their stress when they become anxious or distracted when faced with so many frustrating challenges. Teachers can facilitate personal coping skills and strategies in the form of checklists, models, and reminders (CAST, 2018). Teachers can assist students in developing their self-assessment skills and reflection by helping students recognize their progress by monitoring and graphing data on changes in their own behavior (CAST, 2018). Teachers can support ELs who struggle in academics by focusing on and acknowledging the social, linguistic, and material resources they do use, rather than solely looking at their difficulties (Moschkovich, 2000). 


\section{Provide Options for Sustaining Effort and Persistence}

Learning new skills and strategies requires sustained effort and concentration. ELs may need strategies to support them as they regulate their attention and engage with academic tasks in a new language. Teachers can provide guided practice and support so that students develop sustained effort and persistence by highlighting goals, varying demands and resources, fostering peer collaboration, and providing mastery-oriented feedback (CAST, 2018). To heighten salience of goals and objectives, teachers can present periodic reminders of the goals (CAST, 2018).

\section{Provide Options for Recruiting Interest Within a Safe Learning Environment}

Teachers put considerable effort into attracting students' attention and engaging their interest so that ELs can access and process academic content. Teachers must maintain a balance between tailoring their instruction to meet both instructional goals and standards, as well as making the content personally relevant to students. With this guideline in mind, students are given choices for how they reach the learning objective and the amount of support that is available to them (CAST, 2018). Teachers must be careful to assign appropriate expectations for all students, but especially ELs. They must take into consideration students' language ability and give them options that help them achieve their goals and learning objectives. When students choose an option that is engaging to them, they must feel safe and supported in their learning so they can express what they know. Teachers create safe and respectful spaces so students can concentrate on the learning process (CAST, 2018). A positive learning environment is one that reduces threats and negative distractions, even subtle ones, so that students can access the information. Teachers can minimize threats and distractions by having clear expectations about how to be respectful to others.

In the following section, we share practical application of the UDL framework guidelines for engagement in our work with elementary and secondary ELs, as presented in two illustrative case vignettes based on our teaching experience. For both Cho and Hector, we list specific ways that teachers provide options for self-regulation, options for sustaining effort and persistence, and recruiting interest in a safe learning environment.

\section{Connecting UDL to the Elementary Classroom: Cho}

Due to his background, trauma in the refugee camp, and transition to the United States, Cho has trouble regulating his emotions and interacting with his peers; this often leads to misunderstandings with his second-grade peers and teachers. When he cannot communicate his desires and requests, he becomes extremely upset and starts sobbing uncontrollably or becomes physically aggressive. His teachers have begun to anticipate these reactions in the classroom and are teaching him some techniques with which he can deal with his emotions.

Taking an assets-based approach, the ESL specialist notices the abilities that Cho has and what he already knows and determines how she can incorporate these abilities into her instruction as the school staff supports Cho as he learns new content. The ESL specialist finds that Cho was extremely empathetic, and even though he does not communicate clearly right away, he does what he can to help other students who are struggling both on the playground and in the classroom. For example, Cho sees a student on the playground who has fallen while playing. He does not simply ask if he is hurt; instead, he helps him up and tries to rub his back to make him feel better. The ESL specialist also notes that Cho enjoys engineering tasks such as taking things apart and putting things together. She uses this strength to have him help other students using a "show, then tell" model. He shows other students how to do a task with manipulatives, then a teacher or peer tells him what he is doing and he repeats it. This social and academic interaction with his peers both encourages Cho to be engaged and attaches language to a process in which he is confident. 
Teachers help Cho develop self-regulation skills by accompanying him on short breaks from the classroom environment while he processes situations and emotions as his language develops. The general education teacher recognizes the trauma that he has experienced and has connected him with a counselor to work on how he reacts to different obstacles or problems. Additionally, Cho's teachers provide reminders for his coping skills by using visual cues during small group and whole group times. By illustrating strategies such as deep breathing, walking to the water fountain, or separating himself from the group, Cho is allowed to work through his emotions. The pictures might be posted on a wall near the door or in his folder. Each of his teachers has his or her own system with him and how he communicates his needs. Sometimes he may initiate the use of one of his strategies, and other times his teachers may need to remind him. His teachers help him recognize his progress by using charts to visually show his increased ability to stay in the classroom, interact with peers, and communicate his needs effectively. As his language continues to grow, the use of a morning, lunch, and afternoon check-in conversation has become increasingly helpful.

Cho also perseveres when given consistent positive feedback from his teachers. Giving Cho targeted feedback with specific examples helped him to understand what he did right. For example, when working with peers, Cho would respond to feedback such as, "I noticed that you were able to work with your partner in a focused and kind way." Specific words such as kind, effective, focused, ontask, and so on needed to be pretaught to Cho so that he could fully understand the targeted feedback. This was more beneficial than generic encouragement and his teachers noticed that he would repeat the behaviors or skills that earned him positive feedback.

For Cho, using a picture/word journal shows his progress and allows him to see how far he has come. In the beginning, he drew basic pictures to express himself. As his literacy skills began to grow, he labeled pictures and wrote sentences. Over time, this type of tool motivated Cho and provided feedback on his progress.

As Cho gained greater proficiency with the English language, he was given choices to achieve his learning goals. In writing, he was given options to illustrate his ideas first, use graphic organizers, or give an oral presentation to his teacher. When he realized that he could complete the assignment that his peers were doing, just in a different way, his confidence grew and he began to desire to try to complete assignments in multiple ways. He would receive help with a writing assignment, but would still want to give an oral presentation to the teacher or illustrate what he had learned. The classroom teacher worked closely with the ESL specialist to help with these assignments. The ESL specialist used Collier's (2011) checklists to better understand Cho and plan lessons with his diverse background in mind, as well as to find important points of engagement for him. The Language Interaction Checklist, Sociocultural Need Checklist, and Acculturation Checklist that Collier (2011) developed enabled Cho's teachers to understand him as a person and not simply a student. Once they understood the dynamics of his background, home life, and acculturation rate, they were able to better understand how he learns and what he brings to the classroom. His teachers were also able to determine some of his needs outside of the classroom.

\section{Connecting UDL to the Secondary Classroom: Hector}

Although Hector had never been exposed to formal education, he exhibits a willingness and desire to learn. When given an assignment, he wants to complete his tasks efficiently and accurately. He asks his teachers to sit and work one-on-one with him when unsure of how to approach a task. Hector shows success, especially in mathematics, when he receiving individualized attention while learning. This, however, leads to Hector getting frustrated when his teachers work with other students and cannot give him the personal time he wants. This has led to Hector's current work on self-regulation. He sees both in-school and out-of-school counselors to help with the traumas he has experienced coming to the United States as an unaccompanied minor and assist with developing self-regulation 
in all environments. He also has a history of getting too close to females and making inappropriate gestures around women.

Hector's ESL math teacher uses an assets-based approach to use the abilities that Hector has and what he already knows and determines how she can incorporate these abilities into her instruction as the school staff supports Hector in learning new content. In his first 5 months of school, he has become more accepting of people's requests for him to give them more space. Additionally, he has begun to self-regulate how he approaches other people's personal space. Now, his math teacher rarely has to ask him to take a few steps back when he comes to ask for help. He is still working on developing patience when his teachers are working with other students, but they do see progress in how he is conducting himself in class. He has learned to say "excuse me" when he wants his teacher's attention when they are working with other students instead of just pushing his peers aside.

With his first exposure to school being at the high school level, Hector was always behind his peers. While they were making progress and building on prior skills and knowledge, Hector had to learn everything from the foundational level. At times, he would become quite frustrated and have tears in his eyes. He had to be taught how to add and subtract while his peers were able to perform more complex mathematical operations. To encourage him to persist, Hector's math teacher gave similar assignments but adjusted the rigor so that he would feel capable. This gave him the confidence that he could participate in similar ways to his peers without being obviously behind academically. Additionally, Hector's teachers reward him for small success on the way to achievement of goals to sustain effort his effort. Hector's math teacher made explicit mention of his success and progress during class as his proficiency and confidence grew. His initial tendencies were to try to shy away from classroom participation, but when he did raise his hand to answer, he was praised for his contributions to class. Hector's confidence in his abilities grew each time. As Hector became more skilled in the classroom, he received more encouragement from both his teachers and his peers. His effort and persistence improved with each success.

Hector's teachers foster peer collaboration and communication to provide support for sustained engagement. Hector received some small-group instruction in the ESL classroom. As the class enrollment grew, the teacher recruited the help of a student tutor, who had study hall at the time, to work one on one with Hector. Hector craved attention and support from his teachers and began to believe he was able to do it with constant affirmation. While many of Hector's teachers pushed for an Individualized Education Program because they did not know how else to meet his needs, other teachers worked with him and supported his development through one-on-one instruction and identified other students who could help him. Once he knew there was support and a caring environment in certain classrooms, he was able to make significant progress. In other classes, he was unwilling to work because he was not getting positive messages about his abilities from his teachers and peers.

Hector can choose between types of homework offered each night. Students have a choice between a traditional pen-and-paper option, an online option, or an art project or other representation of the math concepts. All students are given these choices and decide what is best for them for that concept and that night. These homework options first began through the collaboration between a general education teacher and an ESL specialist in math to encourage students to be more successful at homework and to allow them to express their ideas in a variety of ways. Hector enjoys being able to choose his assignments and works well on things he is confident that he understands. He does not always have the skill of perseverance, though, and sometimes gives up when he cannot grasp the task. This is much more evident in large classroom settings where he does not get the individual attention that he needs to make progress. 


\section{Professional Collaboration in a UDL Framework}

In our experience, collaboration among teachers has been key to providing ELs with choice and support in achieving learning objectives. Teacher/specialist collaboration can be enhanced when everyone has the UDL principles in mind to plan instruction, activities, and assessments.

Professional collaboration can significantly increase the available support and scaffolding for students' sustained engagement. Specialists and general education teachers can work together to make appropriate activities and tasks in an accepting and supportive environment, which increases student engagement.

Because the backgrounds of ELs are so diverse, potential motivators or distractions are varied as well. Teachers must familiarize themselves with the families, cultures, and school experiences that each student brings to the classroom (Collier, 2011). Familiarizing themselves in this way helps them to better understand their students and to create appropriate safe spaces. Also, this information should not be kept to one person, but, instead, respectfully shared with specialists and other teachers who may be working with these students. This type of collaboration can only help students adjust and be able to focus on learning.

\section{The Role of Families in a UDL Framework}

Gathering information from the family about the student is an important step in investigating the lack of progress in the general education classroom when an EL is referred for special education. Acculturation and knowledge of the student's background is integral to determining a possible learning disability. We cannot automatically assume that students cannot do the work because of their lack of abilities. According to Collier (2011), there are many other factors of acculturation that may be affecting their performance in the classroom, including culture shock, anxiety, native language, educational background, and so forth. Teachers must get to know their students' backgrounds before making any generalizations or claims. They can do this by meeting consistently with the families or guardians about their students' progress and asking them to complete a simple parent questionnaire to learn more about students' home life, past education experiences, and proficiency in their native language. The ESL specialist may need to collect supplementary and specific data, in addition to the information collected during school registration, to more fully understand the student's context. The extra information gathered by the ESL specialist must be used for instructional decisions to benefit the student and increase cultural competence (Collier, 2011).

\section{Conclusion}

Cho and Hector have learning needs much different from their peers and have not responded to classroom instruction as expected. Teachers may be tempted to refer ELs for special education services when these students do not progress as quickly as their peers or they need additional behavioral and social-emotional support.

Cho was referred for special education testing, but moved out of state before he was tested. In just over 1.5 years in the United States, Cho was reading and comprehending at a mid-second-grade level. He was able to hold complex conversations with both peers and adults and would be the first to admit if he did not understand what was going on or what was expected of him. However, he did struggle with working independently and staying on task in the regular education classroom.

Hector was referred for special education testing within his first 2 months of school. The basis for referral was to help support Hector with emotional and behavioral issues that stemmed from a very difficult and traumatic childhood. Hector was not identified as needing special education services. It 
is apparent that, with individual attention and modification of curriculum to meet his needs, Hector can be successful.

Both Cho and Hector show how important it is to understand how different the learners in any classroom are. No two ELs are the same, nor will they learn or be engaged in exactly the same way. UDL attempts to eliminate barriers and allows the content to be accessible to all students, not only those in special education. UDL is made specifically for learners with different profiles and can be used in regular education classes, special education, and ESL settings.

Table 1 summarizes what teachers at both the elementary and secondary level can do to use the strengths and resources of ELs and engage them academically.

Table 1. Multiple Means of Engagement for English Learners at the Elementary and Secondary Levels

\begin{tabular}{|c|c|c|}
\hline $\begin{array}{l}\text { Universal Design for } \\
\text { Learning Guideline }\end{array}$ & Elementary & Secondary \\
\hline $\begin{array}{l}\text { Options for self- } \\
\text { regulation }\end{array}$ & \multicolumn{2}{|c|}{$\begin{array}{l}\text { Discuss and monitor self-regulation techniques in the classroom } \\
\text { Work on individual coping skills with counselors in school and outside of } \\
\text { school }\end{array}$} \\
\hline \multirow[t]{3}{*}{$\begin{array}{l}\text { Options for sustaining } \\
\text { effort and } \\
\text { persistence }\end{array}$} & $\begin{array}{l}\text { Offer concrete manipulatives and } \\
\text { visuals to supplement auditory } \\
\text { information }\end{array}$ & Enlist a peer tutor to help \\
\hline & $\begin{array}{l}\text { Give targeted and specific positive } \\
\text { feedback }\end{array}$ & $\begin{array}{l}\text { Give frequent praise, both } \\
\text { publicly and privately, as } \\
\text { student shows any progress } \\
\text { toward goals and mastery }\end{array}$ \\
\hline & Picture/word journal & $\begin{array}{l}\text { Offer similar assignments, } \\
\text { adjusted for ability level }\end{array}$ \\
\hline \multirow{2}{*}{$\begin{array}{l}\text { Options for recruiting } \\
\text { interest within a } \\
\text { safe learning } \\
\text { environment }\end{array}$} & $\begin{array}{l}\text { Gather additional data on students' } \\
\text { sociocultural needs and level or } \\
\text { acculturation }\end{array}$ & $\begin{array}{l}\text { Offer choice through } \\
\text { homework options }\end{array}$ \\
\hline & $\begin{array}{l}\text { Create safe spaces by providing time } \\
\text { for breaks and check-ins with } \\
\text { specialists }\end{array}$ & $\begin{array}{l}\text { Create safe spaces by giving } \\
\text { positive messages to } \\
\text { students about their effort } \\
\text { and progress }\end{array}$ \\
\hline
\end{tabular}

Rather than focusing on deficits, teachers can reframe their thinking to consider the differences in student thinking and execution of academic skills (Lewis, 2014). All students have areas of strengths and vulnerabilities. Instead of immediately testing an EL to determine if the student is eligible for special education, teachers and support staff can employ the UDL principle of engagement in the prereferral process by providing a safe space to learn, by offering relevant choices that connect to individual students' strengths and interests, and by looking to the family and community for additional resources to understand and support our students. 


\section{References}

Center for Applied Special Technology (CAST). (2018). Universal design for learning guidelines, Version 2.2. Retrieved from http://udlguidelines.cast.org

Center for Applied Special Technology (CAST). (2015, May 13). Teaching ELLs: UDL strategies that work! [Webinar]. Retrieved from http://www.cast.org/udlcourse/Teaching_ELLs_Webinar_5.13.15/index.html

Civil, M. (2007). Building on community knowledge: An avenue to equity in mathematics education. In N.S. Nasir \& P. Cobb (Eds), Improving access to mathematics: Diversity and equity in the classroom (pp. 105 - 117). New York, NY: Teachers College Press.

Clarke, K., Huang, J., Milczarski, E., \& Raby, C. (2011). The assessment of English language learners with learning disabilities: Issues, concerns, and implications. Education, 131, 732739. doi: 10.1080/00098655.2011.590550

Collier, C. (2011). Seven steps to separating difference from disability. Thousand Oaks, CA: Corwin.

Klingner, J., \& Eppolito, A. (2014). English language learners: Differentiating between language acquisition and learning disabilities. Arlington, VA: Council for Exceptional Children.

Koestler, C. (2012). Beyond apples, puppy dogs, and ice cream: Preparing teachers to teach mathematics for equity and social justice. In A.A. Wager \& D.W. Stinson (Eds.), Teaching mathematics for social justice: Conversations with educators (pp. 81 - 97). Reston, VA: National Council of Teachers of Mathematics.

Lewis, K. E. (2014). Difference not deficit: Reconceptualizing mathematical learning disabilities. Journal for Research in Mathematics Education, 45, 351-396. doi:10.5951/jresematheduc.45.3.0351

Maxwell, L. A., \& Shah, N. (2012). Evaluating ELLs for special needs a challenge. Education Week. Retrieved from https://www.edweek.org/ew/articles/2012/08/29/02ell_ep.h32.html

Meo, G. (2008). Curriculum planning for all learners: Applying universal design for learning (UDL) to a high school reading comprehension program. Preventing School Failure, 52, 21-30. doi:10.3200/PSFL.52.2.21-30

Molle, D. (2015). Academic language and academic literacies: Mapping a relationship. In D. Molle, E. Sato, T. Boals, \& C.A. Hedgspeth (Eds.), Multilingual learners and academic literacies: Sociocultural contexts of literacy development in adolescents (pp. 13-32). New York, NY: Routledge.

Moschkovich, J. N. (2000). Learning mathematics in two languages: Moving from obstacles to resources. In W.G. Secada (Ed.), Changing the faces of mathematics: Perspectives on multiculturalism and gender equity (pp. 85-93). Reston, VA: National Council of Teachers of Mathematics.

National Center on Universal Design for Learning. (2014). About UDL: The three principles of UDL. Retrieved from http://www.udlcenter.org/aboutudl/whatisudl/3principles

Novak, K. (2016). UDL now: A teacher's guide to applying universal design for learning in today's classrooms. Wakefield, MA: CAST Professional Publishing.

Rose, D. H., Harbour, W. S., Johnston, C. S., Daley, S. G., \& Abarbanell, L. (2006). Universal design for learning in postsecondary education: Reflections on principles and their application. Retrieved from http://www.udlcenter.org/sites/udlcenter.org/files/UDLinPostsecondary.pdf

Sullivan, A. L. (2011). Disproportionality in special education identification and placement of English language learners. Exceptional Children, 77, 317-334. 
The Journal of Educational Research and Practice provides a forum for studies and dialogue that allows readers to better develop social change in the field of education and learning. Journal content may focus on educational issues of all ages and in all settings. It also presents peer-reviewed commentaries, book reviews, interviews of prominent individuals, and additional content. The objectives: We publish research and related content that examines current relevant educational issues and processes aimed at presenting readers with knowledge and showing how that knowledge can be used to impact social change in educational or learning environments. Additional content provides an opportunity for scholarly and professional dialogue regarding that content's usefulness in expanding the body of scholarly knowledge and increasing readers' effectiveness as educators. The journal also focuses on facilitating the activities of both researcher-practitioners and practitioner-researchers, providing optimal opportunities for interdisciplinary and collaborative thought through blogging and other communications.

Walden University Publishing: http://www.publishing.waldenu.edu 